\title{
SECURITY BARRIERS IN MANAGEMENT SYSTEM OF WORKERS' OCCUPATIONAL RISKS IN AGRICULTURAL PRODUCTION
}

Levashov Sergey Petrovich, Candidate of Technical Sciences, Associate Professor of the chair "Ecology and Life Safety“, Kurgan State University. Russia.

Belyakin Sergey Konstantinovich, Candidate of Technical Sciences, Associate Professor of the chair "Ecology and Life Safety", Kurgan State University. Russia.

Shkrabak Roman Vladimirovich, Candidate of Technical Sciences, Associate Professor of the chair "Professional Certification and Innovation", St. Petersburg State Agrarian University. Russia
Keywords: safety; occupational hazard; injuries; content management system.

It is presented the methodology of the analysis and forecasting of workers' occupational risks, providing the opportunity to develop and implement preventive measures, aimed at ensuring safe labor environment, as well as at identifying, assessing and reducing these risks.

\section{МАТЕМАТИЧЕСКИЕ МОДЕЛИ ГИДРОТЕРМИЧЕСКОГО РЕЖИМА ВОДОХРАНИЛИЩА-ОХЛАДИТЕЛЯ}

\author{
МАДГАЗИН Рафаэль Жаватович, Geoinformation Monitoring \\ оРЛОВА Светлана Сергеевна, Саратовский государственный аграрный университет \\ имени Н.И. Вавилова
}

В статье приведены мероприятия, эффективно понижающие температуру воды водохранилища-охладителя, на основе расчетов на математических моделях. С целью эффективного использования всей площади водохранилища как охлаждающей емкости целесообразно устроить отводящий канал также и слева от станции ГРЭС длиной не менее 1 км, при этом существующий канал, отводящий нагретую воду, должен быть длиной не менее 2 км. В результате этих мероприятий температура на глубинном водозаборе теоретически может составить $15,7^{\circ} \mathrm{C}$. При устройстве отводящего канала длиной более 1 км шириной около 800 м с иироким водосливом только на левом берегу и ликвидации канала на правом берегу водохранилища возможно падение температуры на глубинном водозаборе до $15,9{ }^{\circ} \mathrm{C}$.

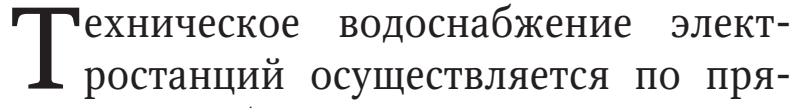
моточной и оборотной схемам с использованием естественных или наливных водоемов-охладителей, градирен и брызгательных устройств. Вода на тепловых станциях используется для уменьшения температуры и давления пара на выходе из турбин. При прохождении охлаждающих устройств она нагревается и со сравнительно небольшими потерями возвращается обратно в водоем, где охлаждается и снова попадает в теплообменники.

Водоемы-охладители являются наиболее эффективными охладителями воды, т.к. обладают техническими и экономи- ческими преимуществами по сравнению с другими охладителями [6].

Однако по гидравлическим и гидротермическим показателям процессы, проходящие в водоемах-охладителях, являются самыми сложными в регулировании тепло- и массообмена.

Сам гидротермический режим, а соответственно и степень охлаждения потока зависит от целого ряда факторов, таких как мощность электростанции, сопровождающаяся повышением расхода или температуры циркуляционной воды, в результате которой увеличиваются теплопотери; испарение, скорость течения и ветрового воздействия; влияние измененных конструктивных решений 
гидротехнических сооружений при эксплуатации [5].

Основными источниками снижения эффективности эксплуатации станции являются не сами прямые затраты на ремонт станции, а явления, вызванные повреждениями, которые снижают охлаждающую способность водоема-охладителя, приводя к повышению температуры воды на входе в конденсаторы турбин. Повреждения в конечном итоге ухудшают вакуум и тем самым снижают экономический эффект эксплуатации электростанции. Повышение температуры охлажденной воды на $1{ }^{\circ} \mathrm{C}$ приводит к перерасходу $1,2 \ldots 2,0$ г (кВт.ч) топлива.

Применяемые в настоящее время расчетные методы оценки охлаждающей способности водоемов-охладителей не учитывают всего многообразия факторов. Наиболее полный метод, охватывающий все стороны влияния работы системы водоснабжения в конкретных условиях на эффективность работы электростанции, связан с постановкой комплексных натурных исследований, раздельно оценивающих влияние всех показателей эксплуатации станции.

В настоящей работе рассматриваются результаты комплексного обследования состояния сооружений, влияющих на охлаждение воды в водохранилище и результаты модельных расчетов.

В качестве пруда-охладителя Экибастузская ГРЭС-1 использует водохранилище, созданное в котловине мелководного озера Женгельды. Водохранилище заполняется из канала им. К. Сатпаева. Для охлаждения конденсаторов Экибастузской ГРЭС-1 требуется около 4 млрд $\mathrm{M}^{3}$ воды в год.

Летом охладитель работал неудовлетворительно: на выходе из конденсаторов в отводящий канал максимальная температура воды составляла $37{ }^{\circ} \mathrm{C}$, на водозаборе $24,4^{\circ} \mathrm{C}$. В основном глубина водохранилища составляет около 3 м, лишь на незначительной площади, у водоприемника, около 8 м. Часть водохранилища, примыкающая к территории ГРЭС, огорожена дамбой и служит в качестве сбросного канала, отводящего «горячую» воду в водохранилище. Длина отводящего канала $850 \mathrm{M}$, ширина около $5 \mathrm{~m}$.

По первоначальному проекту канал должен быть с водонепроницаемым бортом.
Фактически ограждающая дамба выполнена водопроницаемой в расчете на возникновение стратифицированного водного потока. Стратифицированный поток воды характеризуется наличием явно выраженных слоев, имеющих различную температуру по вертикали. Теоретически, верхний «горячий» слой воды, профильтровавшейся сквозь ограждающую дамбу, должен продвинуться на значительное расстояние от канала - и, охладившись, поступить в водоприемник.

Как показали обследования и результаты измерений, стратификация воды по вертикали отсутствует. Вытекающая вода из конденсаторов, не охлаждаясь, просачивается через ограждающую дамбу - левый борт отводящего канала и напрямую попадает в водоприемник.

Одним из простых и экономичных решений данной проблемы могла бы стать гидроизоляция ограждающей дамбы, которая сделает ее водонепроницаемой и исключит попадание неохлажденной воды в водоприемник. Однако исследования, выполненные решением обратных задач на математических калибровочных моделях, показали, что даже при гидроизоляции отводящего канала температура на водозаборе будет недопустимо высокой и не будет соответствовать техническим требованиям эксплуатации.

Поэтому на математических моделях рассмотрены следующие возможные варианты снижения температуры воды в водохранилище-охладителе:

1) определение наиболее эффективной длины существующего отводящего канала на правом борту водохранилища-охладителя;

2) определение картины теплового потока в водохранилище при устройстве отводящего канала различной длины слева от станции при совместной работе с существующим каналом (справа от станции);

3) определение картины теплового потока в водохранилище при устройстве нового отводящего канала различной длины слева от станции и ликвидации существующего;

4) устройство нового канала (слева от станции) с широким порогом. 
При однородно-изотропной области установившийся режим теплового потока описывается уравнением теплопроводности в частных производных второго порядка Лапласа $[1,2,7]$ :

$$
\frac{d^{2} T}{\mathrm{~d} x^{2}}+\frac{\mathrm{d}^{2} T}{\mathrm{~d} y^{2}}=0
$$

Аналитического решения уравнения (1) не существует $[2,3]$. В связи с этим уравнение Лапласа решалось приближенным, численным методом преобразованием к виду $[2,3]$

$$
T_{x, y}=\left(T_{x+1, y}+T_{x-1, y}+T_{x, y+1}+T_{x, y-1}\right) / 4,(2)
$$

где $T_{x, y}$ - величина температуры потока в центре расчетного узла; $T_{x-1, y} ; T_{x+1, y} ; T_{x, y+1} ; T_{x, y-1}$ - величины температуры в вершинах прямоугольных сеток, на которые разбита площадь поверхности водохранилища: для решения уравнения (2) в конечных разностях расчетную область делили на ряд элементов потока построением квадратной сетки [1-3].

В связи с тем, что трехметровая глубина воды составляет более 90 \% площади водохранилища, принято выполнить расчеты на плановой однородной модели без учета мощности водного потока.

Линии направления теплового потока строили с учетом выполнения условий Коши-Римана [8]:

$$
\frac{d \psi}{d x}=\frac{d T}{d y},
$$

на которых $\psi=$ const.

Непроницаемые границы (контур водохранилища) являются линиями направления движения теплового потока (линии тока), поэтому вдоль них функция тока имеет постоянное значение, а температурный градиент по нормали к этой границе равен нулю. Поэтому [1, 4] по контуру водохранилища модели задавалось условие (4).

В результате выполнения итерационных процессов методом Либмана в каждом узле расчетной области получали ряды, в которых для устойчивости решения должно выполняться условие

$$
\lim _{\mathrm{n} \rightarrow \infty}\left(T_{x, y}^{\mathrm{n}+1}-T_{x, y}^{\mathrm{n}-1}\right) \rightarrow 0,
$$

т.е. должна выполняться сходимость чисел, представляющих в каждом узле расчетной области ряды из расчетных величин $T_{x, y^{*}}$.

Устойчивость решения и выполнение условия (5) обеспечивались явной схемой центральной конечно-разностной аппроксимацией дифференциальных уравнений, преобразованных к разностному виду (2).

Для достижения заданной точности решения итерационный процесс продолжался до выполнения условия

$$
T_{x, y}=T_{x, y}^{n+1}-T_{x, y}^{n-1} \leq 0,000001,
$$

когда разность результатов настоящего и предыдущего значений $T_{x, y}^{n+1}-T_{x, y}^{n-1}$ в узле не превышает заданной точности расчетов.

Расчеты выполнены при следующих граничных условиях:

на выходе воды из конденсаторов в отводящий канал задавали граничное условие первого рода - температура, измеренная для самого жаркого периода $37^{\circ} \mathrm{C}$;

на водозаборе задано граничное условие четвертого рода - температура воды, измеренная для самого жаркого периода, $24,4^{\circ} \mathrm{C}$. Задавали граничное условие подгонкой через «фильтрационное сопротивление» температура $0{ }^{\circ} \mathrm{C}$. Температуру $24,4{ }^{\circ} \mathrm{C}$ подгоняли на калибровочной модели. При удлинении канала отводящей воды температура на водозаборе изменялась так, что заданная температура через «фильтрационное сопротивление» $0{ }^{\circ} \mathrm{C}$ не влияла на выходную температуру (подобно радиусу влияния при работе водозаборной гидрогеологической скважины).

Расчетную область делили на две модели: модель водохранилища и модель канала:

1) расчетную область модели водохранилища разбивали на квадратную сетку с шагом $40 \mathrm{M}$;

2) расчетную область вторых моделей (моделей каналов) разбивали на сетку с шагом 2 м. Модели каналов имели масштаб в 20 раз крупнее основы;

3) обе расчетные модели объединялись в единую соответствующими уравнениями.

Результаты расчетов представлены ниже в виде термодинамических сеток теплового потока: вариант с водонепро- 


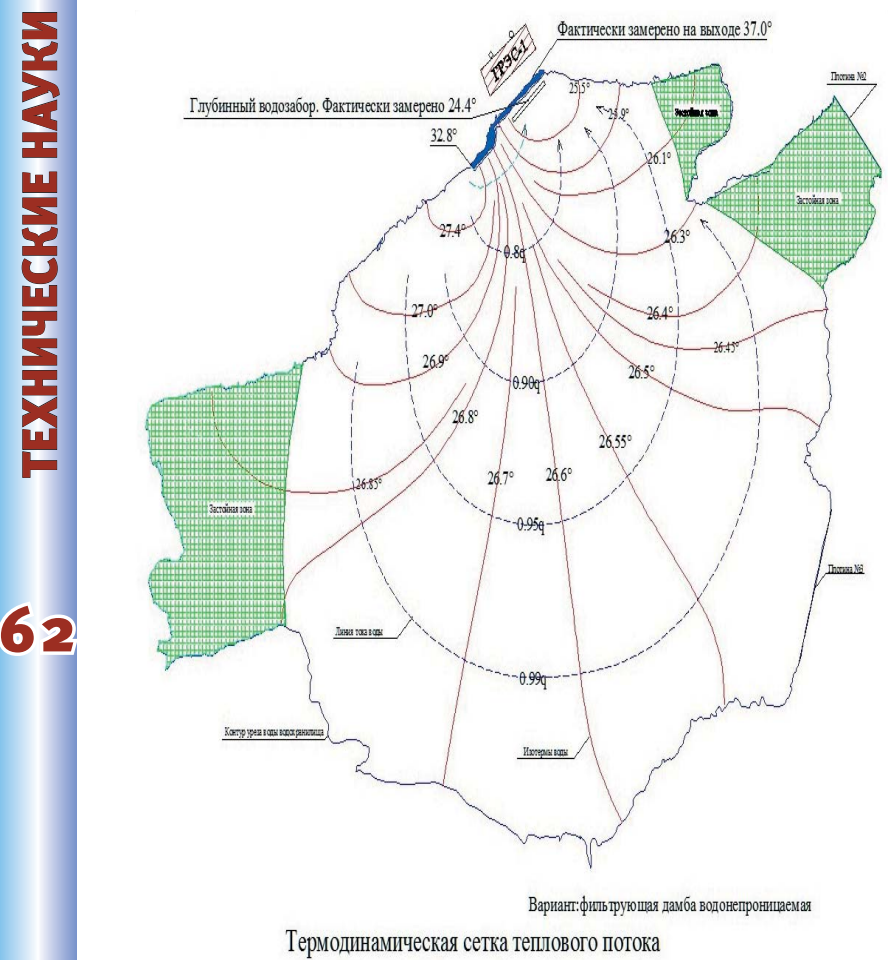

Рис. 1. Калибровочная модель

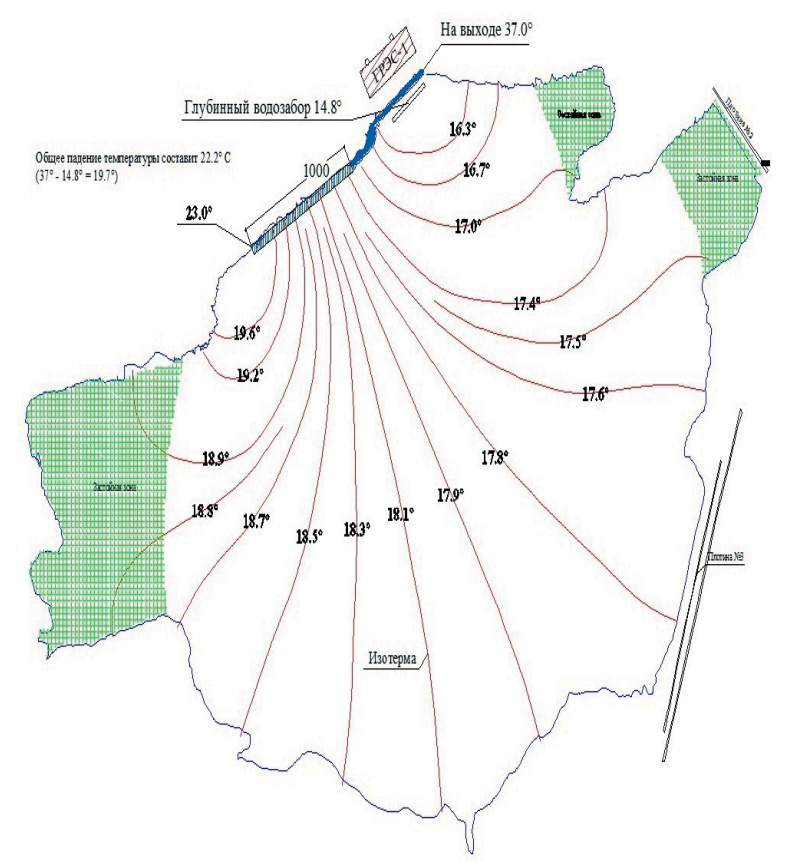

Вариант: отводящий канал удлпннен на 1000 метров

Картина динамики теплового поля

Рис. 2. Отводящий канал удлинен на 1000 м

ницаемой фильтрующей дамбой (рис. 1), вариант удлинения существующего отводящего канала на 1000 м (рис. 2), вариант удлинения отводящего канала на 1000 м и устройства канала на правом берегу длиной 500 м (рис. 3) и вариант орга2 низации отводящего канала на левом бе2017 регу с ликвидацией существующего канала (рис. 4).

При увеличении длины отводящего канала температура воды снижается, что отражено на графике зависимости падения темпе-

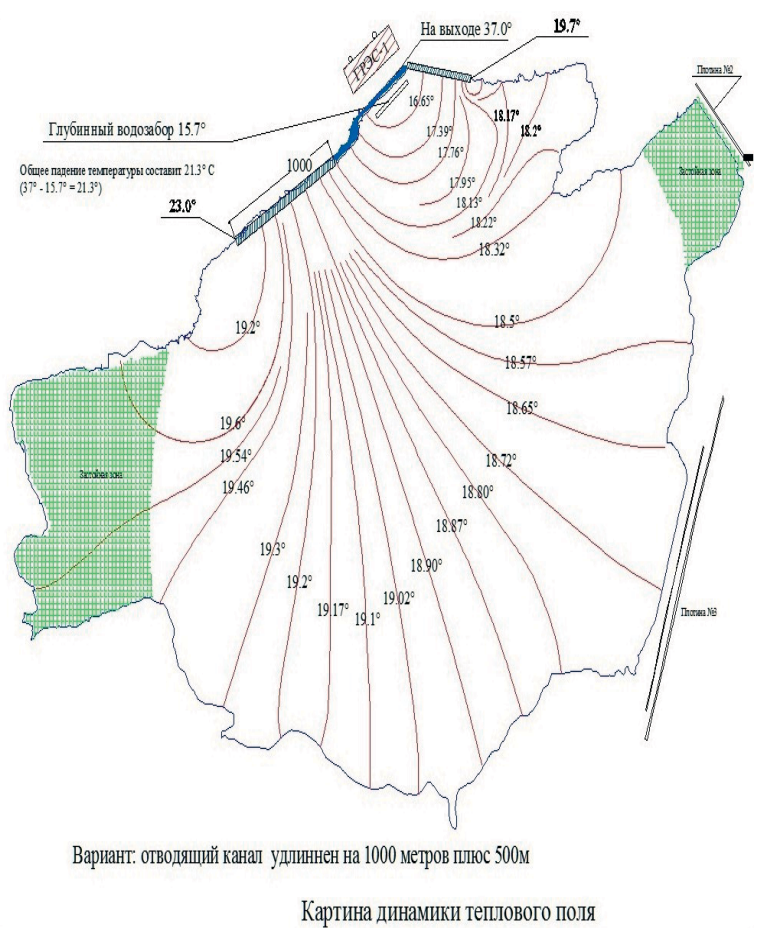

Рис. 3. Отводящий канал удлинен на 1000 м, на левом берегуустроен канал длиной 500 м

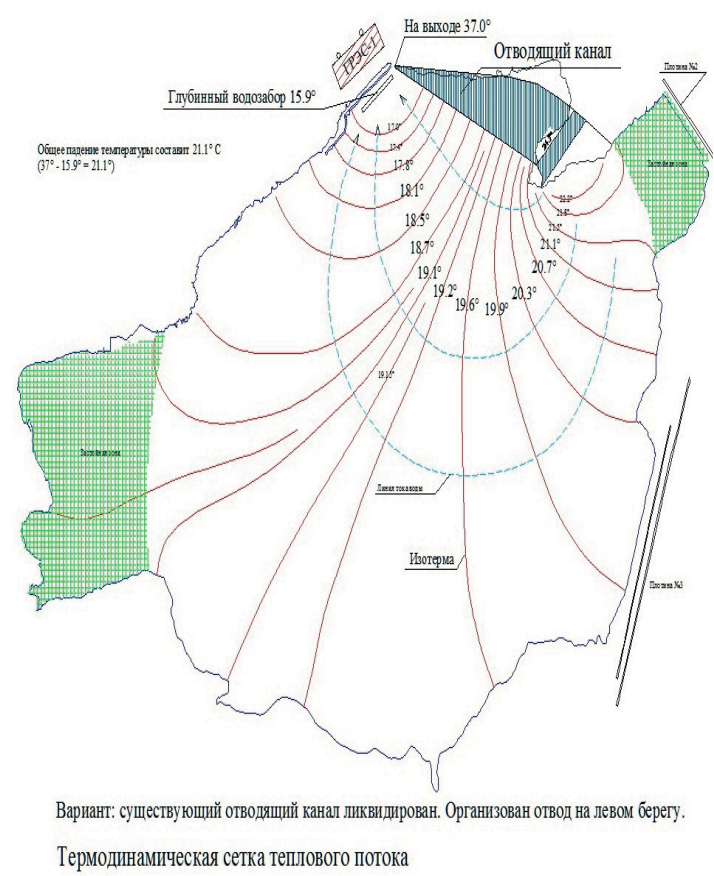

Рис. 4. Отвод «теплой воды» организован слева от станиии

ратуры на водозаборе от длины отводящего канала (рис. 5).

Из рис. 5 видно, что резкое падение температуры происходит при длине канала около 1200 м, следовательно, удлинять канал на большую длину будет экономически не выгодно.

Таким образом, на основании вышеизложенного можно сделать следующие выводы.

1. Существующий канал, отводящий нагретую воду должен быть длиной не менее 2 км. При этом температура на глубинном 


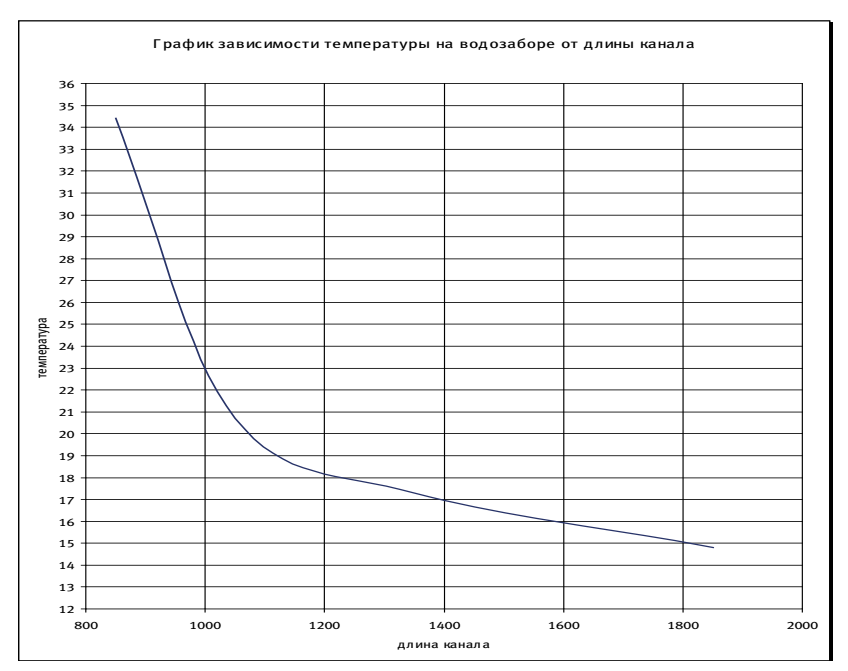

Рис. 5. График зависимости падения температуры на водозаборе от длины отводящего канала

водозаборе теоретически может составить $15,7^{\circ} \mathrm{C}$.

2. С целью эффективного использования всей площади водохранилища как охлаждающей емкости целесообразно устроить отводящий канал также и на левом берегу водохранилища. Длина отводящего канала на левом берегу должна быть не менее 1 км.

3. При устройстве отводящего канала длиной более 1 км шириной около 800 м с широким водосливом только на левом берегу и ликвидации канала на правом берегу водохранилища возможно падение температуры на глубинном водозаборе до $15,9^{\circ} \mathrm{C}$.

4. Для более эффективного использования канала в охлаждении воды рекомендуется выполнить концевой участок канала в виде водослива с широким порогом. Конструкцию концевого участка канала рекомендуется определить на гидравлических моделях.

\section{СПИСОК ЛИТЕРАТУРЫ}

1. Бочевер Ф. М., Гармонов И. В., Лебедев А.В. Основы гидрогеологических расчетов. - М.: Недра, 1965. - 309 с.

2. Калиткин Н.Н., Корякин П.В. Численные методы. в 2 кн. Кн. 2. Методы математической физики: учебник для студ. учреждений высш. проф. образования. - М.: Академия, 2013. 304 c.

3. Кузнецов Г.В., Шеремет М.А. Разностные методы решения задач теплопроводности. Томск: изд-во ТПУ, 2007. - 172 с.

4. Мироненко В. А. Динамика подземных вод: учебник. - 3-е изд. - М.: Изд-во Моск. ун-та, 2001. - 519 c.

5. Орлова С.С. Анализ состояния прудов и малых водохранилищ в период эксплуатации // Научная жизнь. - 2015. - № 4. - С. 47-54.

6. Орлова С.С. Биологические методы понижения температуры в водохранилищах-охладителях // Научная жизнь. - 2016. - № 3. С. $61-67$.

7. Полубаринова-Кочина П.Я. Теория движения грунтовых вод. - М.: Наука, 1977. - 664 с.

8. Свешников А.Г., Тихонов А.Н. Теория функций комплексной переменной. 6-е изд., стереотип. - М.: ФИЗМАТЛИТ, 2008 - 336 с.

Мадгазин Рафаэль Жаватович, главный спещзиалист, Geoinformation Monitoring. Республика Казахстан.

050000, Республика Казахстан, г. Алматы, Ауэзовский район, Толе би, 301.

Тел.: 87272831185.

Орлова Светлана Сергеевна, канд. техн. наук, доцент кафедры «Строительство, теплогазоснабжение и энергообеспечение», Саратовский государственный аграрный университет имени Н.И. Вавилова. Россия.

410056, г. Саратов, ул. Советская, 60.

Тел.: (8452) 74-96-01.

Ключевые слова: водохранилище-охладитель; температура; канал; математические модели.

\section{MATHEMATICAL MODELS OF HYDROTHERMAL REGIME OF THE RESERVOIRS-COOLERS}

Madgazin Rafael Javatovich, Chief Specialist of the firm "Geoinformation Monitoring". Republic of $\mathrm{Ka}$ zakhstan.

Orlova Svetlana Sergeevna, Candidate of Technical Sciences, Associate Professor of the chair "Construction, Heat and Gas Supply, Power Supply", Saratov State Agrarian University named after N.I. Vavilov. Russia.

Keywords: reservoir-cooler; temperature; channel; mathematical model.

The article presents the results of elaboration of measures, effectively lowering the temperature of the water in reservoirs-coolers, based on calculations on mathematical models. In order to effectively use the entire area of the reservoir, as the cooling capacity it is advisable to build the outlet channel is also on the left of the station GRES, lengths not less than $1 \mathrm{~km}$, and the existing channel discharging the heated water it should be at least $2 \mathrm{~km}$ in length. As a result of these measures the total temperature on a deep water intake could theoretically will be $15,7^{\circ} \mathrm{C}$. When channel device lengths of more than $1 \mathrm{~km} 800 \mathrm{~m}$ wide with a wide weirs only on the left bank, and the elimination of the channel on the right bank of the reservoir, possible temperature on a deep water intake will be $15,9{ }^{\circ} \mathrm{C}$. 